\title{
Hsp90 Activity Modulation by Plant Secondary Metabolites
}

Authors

Affiliations
Fabrizio Dal Piaz ${ }^{1}$, Stefania Terracciano ${ }^{1}$, Nunziatina De Tommasi ${ }^{1}$, Alessandra Braca ${ }^{2}$

${ }^{1}$ Dipartimento di Farmacia, Università di Salerno, Fisciano (SA), Italy

${ }^{2}$ Dipartimento di Farmacia, Università di Pisa, Pisa, Italy
Key words

- Hsp90

- Hsp90 inhibitors

- plant molecules

- client proteins received Dec. 30, 2014

revised May 13, 2015

accepted May 30, 2015

Bibliography

Dol http://dx.doi.org/

10.1055/s-0035-1546251

Published online July 30, 2015

Planta Med 2015; 81:

1223-1239 ๔ Georg Thieme

Verlag KG Stuttgart · New York .

ISSN 0032-0943

\section{Correspondence}

Prof. Nunziatina De Tommasi

Dipartimento di Farmacia

Università di Salerno

Via Giovanni Paolo II 132

84084 Fisciano (Salerno)

Italy

Phone: + 39089969754

Fax: + 39089969602

detommasi@unisa.it

\section{Abstract}

$\nabla$

Hsp90 is an evolutionarily conserved adenosine triphosphate-dependent molecular chaperone and is one of the most abundant proteins in the cells $(1-3 \%)$. Hsp90 is induced when a cell undergoes various types of environmental stresses such as heat, cold, or oxygen deprivation. It is involved in the turnover, trafficking, and activity of client proteins, including apoptotic factors, protein kinases, transcription factors, signaling proteins, and a number of oncoproteins. Most of the Hsp90 client proteins are involved in cell growth, differentiation, and survival, and include kinases, nuclear hormone receptors, transcription factors, and other proteins associated with almost all the hallmarks of cancer. Consistent with these diverse activities, genetic and biochemical studies have demonstrated the implication of Hsp90 in a range of diseases, including cancer, making this chaperone an interesting target for drug research.

During the last few decades, plant secondary metabolites have been studied as a major source for lead compounds in drug discovery. Recently, several plant-derived small molecules have been discovered exhibiting inhibitory activity towards Hsp90, such as epigallocatechin gallate, gedunin, lentiginosine, celastrol, and deguelin. In this work, an overview of plant secondary metabolites interfering with Hsp90 activities is provided.

\section{Abbreviations}

$\nabla$

17-AAG: 17-allylamino-17-

demethoxygeldanamycin

AhR: aryl hydrocarbon receptor

Akt: protein kinase $B$

BBM: berbamine

CEP: cepharanthine

CL: celastrol

17-DMAG: 17-dimethylaminoethylamino-17demethoxygeldanamycin

EGCG: (-)-epigallocatechin-3-gallate

EGFR: epidermal growth factor receptor 1

eNOS: endothelial nitric oxide synthase

ER $\alpha$ : estrogen receptor $\alpha$

GDA: geldanamycin

Her2: human epidermal growth factor receptor 2

HIF- $1 \alpha$ : hypoxia-inducible factor- $1 \alpha$

HRI: heme-regulated eIF2 $\alpha$ kinase

HSF1: heat shock factor-1

Hsp90: heat shock protein 90

LPS: lipopolysaccharide

Met: mesenchymal-epithelial transition factor

NF- $k$ B: $\quad$ nuclear factor-kappaB

NSCLC: non-small cell lung cancer

p-Akt: phosphorylated protein kinase B

PAH: $\quad$ polycyclic aromatic hydrocarbon

PI3K: phosphotidylinositol-3-kinase

Raf-1: proto-oncogene serine/threonineprotein kinase

SPR: $\quad$ surface plasmon resonance

STAT3: $\quad$ signal transducer and activators of transcription 3

TPH: $\quad$ triterpenes from Patrinia heterophylla

VEGF: vascular endothelial growth factor 


\section{Introduction}

$\nabla$

Presently, the effective therapeutic interventions in cancer diseases still remain elusive, thus the identification of new possible molecular target(s) becomes crucial. In the last two decades, attention has been focused on the role of Hsp90, an evolutionary conserved molecular chaperone involved in the regulation, folding, stabilization, activation, and assembly of more than 200 "client" proteins, including apoptosis-related protein kinases, transcription factors, and signaling proteins, directly associated with most of the cancer hallmarks [1,2]. Structurally, Hsp90 is a flexible homodimer including three distinct domains: an $\mathrm{N}$-terminal nucleotide-binding domain where the ATPase activity is mainly located, a middle client protein binding/ATP-hydrolysis regulating domain, and a $C$-terminus domain responsible for dimerization of the protein [3]. Hsp90 exists in different isoforms: two in the cytoplasm, Hsp90 $\alpha$ (the heat shock-induced form) and Hsp90 $\beta$ (the constitutively active form), one localized at the endoplasmic reticulum (94KDa glucose-regulated protein, Grp94), one at the mitochondria (tumor necrosis factor receptor-associated protein 1, TRAP1), and finally the cell surface-bound, cell-released and cell-secreted Hsp90 collectively known as "extracellular Hsp90" (eHsp90). Several data reported in the literature suggest the eukaryotic cytosol Hsp90 $\alpha$ to be the major form involved in cancer, also demonstrating that this isoform may have more diverse action than Hsp90 $\beta$ [4]. In the presence of stressed microenvironments, cancer cells undergo adaptive mutations that lead to an increment of Hsp90 activity. Therefore, in order to obtain a simultaneous disruption of multiple signaling pathways important for the growth and viability of cancer cells, and to induce cellular apoptosis and/or necrosis, the inhibition of the Hsp90 protein folding machinery could represent a multifaceted approach toward the tumor treatment [5-8]. Hsp90 inhibitors are grouped into numerous classes based on individual modes of inhibition which are as follows: i) obstructing the binding of ATP at the ATPase catalytic site, ii) interference in co-chaperone/Hsp90 interactions, iii) blocking the receptor interactions of client/Hsp90 alliances, and iv) intervention in the routes of post-translational modification in Hsp90 $[9,10]$. Regardless of the mechanism, a hallmark of Hsp90 inhibition is the degradation of its client proteins; the inhibition of this chaperone indeed leads Hsp90 client proteins to adopt an aberrant conformation, which triggers their ubiquitination, followed by proteasome-dependent degradation. Therefore, compounds able to downregulate the levels of Hsp90 client proteins are often considered promising Hsp90 inhibitor candidates.

Consistent with the notion that small molecules synthesized by the plant kingdom can be considered evolutionary chosen "privileged structures" since they have evolved in a natural selection process to achieve optimal interactions with biological macromolecules, natural molecules have shown an extraordinary potential as modulators of proteins functions and have been subjected to biological studies aimed at discovering their specific molecular targets and elucidating important signaling pathways [11]. Besides, many plant molecules have a crucial role as pharmaceuticals, according to the current number of drugs based on plant molecules in clinical trials or present in the market, and these molecules depict a source of new leads for drug discovery. Since Hsp90 is situated at the critical intersection of genotypes, environment, and development, it's reasonable to expect that natural products represent a fertile territory for the identification of new Hsp90 inhibitors. Most natural products active as Hsp90 $\alpha$ inhibitors, such as radicicol, GDA, and 17-DMAG, are derived from fungi metabolism and possess the benzoquinone ansamycin (GA) or the resorcinol scaffold (radicicol). They are currently being evaluated in over 80 ongoing or completed clinical trials, offering a promising approach for the treatment of different cancer diseases $[12,13]$.

However, there is still a wide requirement for new Hsp90 inhibitors, and the plant kingdom has been explored in order to find new promising compounds. This review provides a brief excursion of plant secondary metabolites interfering with Hsp90 activities and highlights findings regarding their possible molecular mechanism of action.

\section{Flavonoids \\ $\nabla$}

\section{Flavones and flavonols}

Apigenin, chemically known as 4',5,7,-trihydroxyflavone, is a common flavone widespread in plants of the Asteraceae family and in many fruits and vegetables. This flavonoid possesses various clinically relevant properties, such as antitumor and anti-inflammatory activities [14]. Among its anticancer effects, it has been reported to suppress metastasis, to inhibit cancer and cell proliferation, and to have antiangiogenic properties mediated by the alteration of different pathways [15]. Anyway, it has to be considered that the metabolic activity of the gut microflora on apigenin is often responsible for the modulation of its biological activity as a dietary compound, since it's catabolized into smaller phenolic compounds $[16,17]$. In a study focused on the investigation of the antiangiogenic effect of apigenin, it was found that it suppresses the expression of VEGF in endothelial cells via the degradation of HIF- $1 \alpha$ protein mediated by interference with the Hsp90 chaperoning function [18]. Recently, the in vitro therapeutic potential role of apigenin for the treatment of multiple myeloma has emerged. Different biological techniques reveled that apigenin manifested antiproliferative activity in human multiple myeloma through CK2-mediated phosphorylation of Cdc37, disrupting the Hsp90/Cdc37/client complex via the proteasome pathway [19]. Moreover, its modulation of the chaperone Hsp90 induced the degradation of many kinase client proteins, including RIP1, Src, Raf-1, Cdk4, and Akt.

Chrysin (5,7-dihydroxyflavone) is a naturally occurring flavone found in the plant kingdom (Passiflora caerulea L. and Passiflora incarnata L., Passifloraceae) [20-22] endowed with many biological activities, such as anti-inflammatory, anticancer, and antioxidant $[23,24]$. Although chrysin is a promising antitumor agent, little information is known about its molecular mechanism. It was described that chrysin inhibits the expression of HIF- $1 \alpha$ and VEGF in human prostate cancer DU145 cells [25]. In this study, it was reported that chrysin inhibits the expression of HIF- $1 \alpha$ by multiple pathways, including Hsp90 modulation. In particular, it was able to inhibit the binding of HIF- $1 \alpha$ to Hsp90, resulting in the suppression of HIF- $1 \alpha$ expression [25].

Eupatilin, or 5,7-dihydroxy-3',4',6-trimethoxyflavone, is one of the bioactive components of Artemisia asiatica Nakai (Asteraceae) extracts, which are known to have anti-inflammatory, antioxidant, and antitumor effects [26]. In 2008, it was reported that it has anti-inflammatory activity by targeting the NF- $k$ B pathway. The aim of this study was to gain a better understanding on the molecular mechanism of eupatilin-induced attenuation of intestinal inflammation induced by enterotoxigenic Bacteroides fragilis (ETBF) stimulation in an intestinal epithelial cell culture. In 
particular, it was observed that this flavonoid reduces the activity of NF- $k \mathrm{~B}$ and the expression of proinflammatory mediators through the dissociation of the complex Hsp90/IKK- $\gamma$ [27].

Luteolin (3',4',5,7-tetrahydroxyflavone) is a natural flavonoid contained in many medical herbs and vegetables (e.g., parsley, artichoke, celery, green pepper, and perilla leaf). In recent years, experimental evidences have shown that luteolin has multiple and interesting biological profiles: antitumor, anti-inflammatory, antioxidant, and radical scavenging properties, although the problem of its bioavailability should be considered. In light of the metabolic pathways of luteolin, in vitro studies should be carefully assessed [28-31]. The antitumor activity of this flavonoid has been reported in vitro against different kinds of tumor cells and also confirmed in vivo [30-32]. A recent study ascribed luteolin's proapoptotic effect on carcinoma cells to Hsp90 modulation [33]. In particular, it induces apoptosis of HeLa cells by preventing the association between Hsp90 and STAT3. The binding of luteolin to Hsp90 results in the degradation of $\mathrm{Tyr}^{705}$ - and $\mathrm{Ser}^{727}$-phosphorylated STAT3 through the proteasome-dependent pathway as well as in the degradation of other Hsp90 client proteins such as Akt and IKK. Molecular modeling and SPR approaches suggested the interaction of luteolin with the $\mathrm{N}$-terminal ATP-binding site, showing that it is able to prevent ATP-Hsp90 binding and to inhibit ATPase activity of this molecular chaperone [33]. In 2014, Hong et al. showed luteolin's efficacy as an antitumor agent in NSCLC and this effect is ascribed to the lysosome-dependent degradation of the EGF by inhibiting its interaction with Hsp90 [34]. Luteolin showed a potent anti-inflammatory property in vitro, and it reduced LPS-induced lethality in a mouse endotoxin shock model [35]. In addition, it was found to significantly reduce the LPS-induced release of high-mobility group B-1 (HMGB), a nonhistone chromosomal DNA-binding protein involved in the pathogenesis of several inflammatory diseases, both from mouse peritoneal macrophages and RAW 264.7 cells. Moreover, luteolin also inhibited high-mobility group B-1 translocation from the nucleus to the cytoplasma. This effect was correlated to the destabilization of c-Jun and Akt through the suppression of Hsp90 chaperone activity [35].

The naturally occurring flavonoid quercetin $\left(3,3^{\prime}, 4^{\prime}, 5,7\right.$-pentahydroxyflavone) is a component of many common fruits and vegetables with multiple medicinal properties [36]. However, the actual bioavailability of this compound in vivo remains a controversial point in making an assessment of its biological importance [37]. Anti-inflammatory, antitumor, and antiproliferative activities were reported for quercetin [38-40]. Quercetin is able to prevent or retard tumor growth probably thanks to multifunctional effects, in particular, at the molecular level it, inhibits many ATP binding enzymes, especially kinases such as CDK-4 and PI3K [41]. Treatment with quercetin arrests the growth of cancer cells both in vitro and in vivo, and also exhibits tumor cell selectivity [42]. To date, it is well established that this flavonoid inhibits the heat-induced expression of heat shock proteins in many different cell types (such as human breast carcinoma cells and prostate cancer cells) by affecting HSF1 hyperphosphorylation, DNA binding, and transcriptional activity [43]. Furthermore, quercetin induces cancer cell apoptosis in three different prostate cancer cell lines by downregulating the levels of Hsp90 [44]. Further evidence of quercetin's ability to interact with this chaperone was furnished by a proteomic approach that revealed $\mathrm{Hsp} 90$ as a possible target of this flavonoid [45]. Finally, a downregulation of the level of Her-2/neu protein in Her-2/neu overexpressing human breast cancer SK-Br3 cells, in time- and dose-dependent man- ners, was induced by quercetin treatment. In particular, this effect was ascribed to the polyubiquitination of Her-2/neu and to an increase in interaction between Hsp90 and Her-2/neu [46].

\section{Isoflavones}

Derrubone, a prenylated isoflavone originally isolated from the Indian tree Derris robusta (Roxb ex DC) Benth. (Fabaceae) [47], was identified in 2007 as a new potent C-terminal Hsp90 inhibitor through a high-throughput screening assay of a large chemical library. This screening was based on the measure of Hsp90dependent refolding of thermally denatured firefly luciferase which is catalyzed by the Hsp90 present in rabbit reticulocyte lysate [48]. Biological studies revealed that derrubone inhibits Hsp90 with an $\mathrm{IC}_{50}$ value of $0.23 \pm 0.04 \mu \mathrm{M}$ and possesses potent antiproliferative activity against two human breast cancer cell lines, MCF-7 and SkBr3, with $\mathrm{IC}_{50}$ values of $9 \pm 0.70$ and $12 \pm 0.30 \mu \mathrm{M}$, respectively [48]. Cell-based assays showed that this natural compound causes degradation of Hsp90 client proteins, including Raf-1, Akt, Her2, and ER $\alpha$, in a concentration-dependent manner and does not inhibit the ATPase activity of Hsp70. In addition, derrubone inhibits the interaction of Hsp90 and the oncogenic client protein Cdc37 (cell division cycle protein 37) with HRI in breast cancer cell lines, suggesting, therefore, a potential chemotherapeutic use in human breast cancer [4951]. The effect of derrubone on the Hsp90 protein folding machinery is due to its ability to stabilize Hsp90 client interactions and to prevent the progression of the Hsp90/co-chaperone complex, containing bound client proteins through its cycle [48]. Soon after its discovery, a small collection of selected analogues was synthesized and evaluated for antiproliferative activity, exhibiting only a modest improvement in the biological activity over the natural product [52]. Recently, to further investigate the crucial structural features for Hsp90 inhibition, Mays and coworkers reported the design, synthesis, and biological evaluation of flavones and isoflavone chimeras of novobiocin and derrubone [53]. These studies revealed that the functionality at the 3-position of the isoflavone is essential for the modulation of Hsp90 and, moreover, suggest a different binding mode for the bicyclic ring system present in both natural compounds. In 2014, molecular docking studies performed on four different Hsp90 inhibitors, novobiocin, clorobiocin, EGCG, and derrubone, led to the identification of the specific ATP-binding residues of the C-terminal domain (Leu 665, Leu 666, and Leu 694) as the key amino acids involved in the ligand binding. Among these four natural inhibitors, derrubone showed the highest binding energy for the Hsp90 C-terminal domain [54].

\section{Chalcones}

Butein $\left(3,4,2^{\prime}, 4^{\prime}\right.$-tetrahydroxychalcone) is a chalcone found in the stem bark of cashews (Semecarpus anacardium L., Anacardiaceae), the heartwood of Dalbergia odorifera T. Chen (Fabaceae), and the traditional medicinal herbs Caragana jubata Pall. (Anacardiaceae) and Rhus verniciflua Stokes (Anacardiaceae) [55]. Butein exhibited pleiotropic properties, such as anti-inflammatory effects, in macrophages and adipocytes, probably by inhibiting the NF- $k \mathrm{~B}$ and mitogen-activated protein kinase signaling pathways [56,57] and anti-fibrogenic [58] and anticancer activity [59]. Furthermore, it influences cell proliferation, apoptosis, and the cell cycle in many human tumors, including liver, breast, and pancreatic cancers, suggesting a significant antineoplastic therapeutic potential [60-62]. In a recent study, the antiproliferative activity of this chalcone was evaluated against two different 
drug-resistant cancer cell lines, cisplatin-resistant ovarian cancer cells (A2780cis) and gefitinib-resistant NSCLC cells (H1975). However, even if butein moderately inhibited cell proliferation in a concentration-dependent manner, the Western blot analyses revealed a robust dose-dependent degradation of oncogenic Hsp90 client proteins, Her2, Met, Akt, EGFR, and a small induction of Hsp70 [63]. These results suggested that 3,4,2',4'-tetrahydroxychalcone inhibits the Hsp90 chaperoning function and may represent a therapeutic agent to overcome drug resistance in cancer therapy. In this context, in 2014, the synthesis of some butein analogues and their biological evaluation against gefitinibresistant NSCLC cells (H1975) provided a new bioactive compound with a more potent antiproliferative effect on H1975 cancer cells through Hsp90 inhibition [64].

Flavokawain B is a naturally occurring chalcone isolated from the extract of kava-kava [Piper methisticum (L.) G. Forst, Piperaceae], a native plant to the Pacific Islands used as a social drink and as a traditional remedy, and from Alpinia pricei Hayata (Zingiberaceae), a perennial rhizomatous native to Taiwan commonly used in traditional Chinese food and folk medicine [65]. The antitumor potential of the kava extract chalcones has been referred to epidemiological studies that correlate the consumption of kava root extracts in the Pacific Islands with a lower incidence of cancer $[66,67]$. Different studies have shown that flavokawains (flavokawains $A, B$ and C) are apoptotic inducers and anticarcinogenic agents. Moreover, flavokawain $B$ has been reported to induce apoptosis and to have potent antitumor effects both in vitro and in vivo against several carcinoma cell lines, including prostate, colon, bladder, oral, human osteosarcoma, lung cancer cells, and mesenchymal tumors such as synovial sarcoma and uterine leiomyosarcoma [68-72]. Taken together these data suggest that multiple pathways are involved in flavokawain B-mediated antiproliferative activitity. In particular, recent findings have demonstrated that this promising chalcone inhibits the growth of geftinib-resistant NSCLC, H1975, with an $\mathrm{IC}_{50}$ value of $33.5 \mu \mathrm{M}$ and its antiproliferative activity is correlated to Hsp90 inhibition [73]. Flavokawain B induces the downregulation of EGFR, Met, Her2, Akt, Cdk4, and Hsp90 client proteins and upregulates the cellular level of Hsp70 in a concentration-dependent manner, disrupting the Hsp90 protein folding machinery.

Licorice root has been used in traditional medicine for the treatment of diverse pathological conditions such as bronchial asthma, gastric ulcer, and inflammation [74]. One of the major and biogenetically characteristic chalcones isolated from the root of Xinjiang liquorice, Glycyrrhiza inflate Batalin (Fabaceae), is licochalcone A, which is well known for its biological properties [75]. The antitumor activity of licochalcone A has been discovered against gastric cancer cells and in androgen-independent PC-3 prostate cancer cells by cell cycle arrest and apoptosis induction [76,77]. Furthermore, licochalcone A exerted potent anti-inflammatory effects in in vitro and in vivo models induced by LPS [78]. In 2013, from a screening program of natural compounds for the identification of new potential Hsp90 inhibitors, licochalcone A was found to inhibit, with a modest potency $\left(\mathrm{IC}_{50}=50 \mu \mathrm{M}\right)$, the growth of the $\mathrm{H} 1975$ cancer cell line and to induce the degradation of Hsp90 client proteins such as the signaltransducing proteins Akt, Her2, EGFR, and Met [78]. In this study, a docking pose of licochalcone A bound to the $\mathrm{N}$-terminal ATP binding site of human Hsp90 was also proposed.

\section{Catechins}

Catechins are the major constituents in green tea [Camellia sinensis (L.) Kuntze, Theaceae] (30-42\% of dried weight). EGCG particularly is one of the most abundant polyphenols (50\% of total catechins) and is well known for its antioxidant properties, which is crucial for its preventing activity in cancer and cardiovascular diseases. EGCG has been extensively studied for its capability to inhibit cell proliferation and induce apoptosis in several human cancer cells [79]. In the last decades, many different target and signaling pathways have been demonstrated as a partner of EGCG in various cell lines. The first report on EGCG binding to Hsp90 was in 2005 when Palermo et al., studying the AhR gene transcription, demonstrated that it directly binds Hsp90 to the C-terminus of the chaperone, resulting in a conformational change responsible for a modification of the Hsp90-AhR interaction, leading to the inhibition of AhR transcriptional activation. EGCG seems to interact with the XAP2-bound Hsp90 complex [80]. In 2009, Yin and coworkers studying the binding site of EGCG with Hsp90. Using ATP and novobiocin as reference compounds, they demonstrated that EGCG protects a $C$-terminus Hsp90 fragment from trypsine-catalized lysis [81]. They also stated that EGCG binds at/or near the $C$-terminal ATP binding site on Hsp90 producing the block of chaperone dimerization [81]. In this study, it was also established that EGCG stabilizes the association of Hsp70, Cyp40, and XAP-2 to Hsp90. In this way, EGCG could stabilize the Hsp90 co-chaperones complex. In the same year, Li and coworkers, using a proteolytic fingerprint assay, confirmed that EGCG protected the $C$-terminus from cleavage by high concentrations of trypsin [82]. Thus, EGCG impairs the association of Hsp90/Hsp70 and Hsp90/p23 by directly binding to the C-terminal region, inhibiting the Hsp90 chaperoning function. One year later, other authors carrying out an EGCG-conjugated Sepharose 4B beads pull-down assay confirmed that Hsp90 interacts efficiently with the molecule, stating also that EGCG competes with ATP for binding of the ATPase domain of Hsp90 in MCF7 cell lines. They also studied the expression of Hsp90 both in vitro and in vivo. The immunohistochemistry assay showed that the levels of Hsp90 were decreased in EGCG-treated mice compared with the control [83]. Therefore, evidences on the Hsp90 EGCG binding site are in disagreement. The ability of the EGCG Hsp90 function may not be the only mechanism whereby EGCG exerts its antitumoral activity, as many EGCG targets have been reported [84,85]. Its interaction with Hsp90 may be a common mechanism for several of the proposed targets. Many of the proteins reported to bind to EGCG are Hsp90 client proteins or closely related to this chaperone.

Another polyphenol constituent of green tea, (-)-epicatechin, was reported to induce the activation of eNOS in calcium depleted HCAE cells in an Akt- and Hsp90-dependent manner [86]. Black tea polyphenol phytocomplex, theaflavins, and thearubigins, also extracted from tea, downregulated the expression level of Hsp90 in human leukemic U937 and K562 cells. Following the treatment of these cells with the Hsp90 inhibitor 17-AAG alone or in combination with theaflavins and/or thearubigins, the authors observed the downregulation of the expression of p-Akt, cD1, and cDK2. These data supported the hypothesis that the inhibition of Hsp90 by these polyphenols caused the downregulation of its client proteins [87]. 


\section{Biflavonoids}

SPR analysis was used to evaluate the ability of the biflavonoids isolated from Daphne linearifolia Hart. (Thymelaceae) to interact with Hsp90. These compounds interacted with the immobilized protein with a $K_{\mathrm{D}}$ in the $\mu \mathrm{M}$ range, and sensible differences in their affinity towards Hsp90 were observed. Among biflavonoids, 2"-hydroxygenkwanol A showed the best affinity towards Hsp90 $\left(K_{\mathrm{D}} 0.5 \pm 0.10 \mu \mathrm{M}\right)$ compared to the other tested compounds. The presence of a hydroxyl group on C-2" increases the stability of the biflavonoid/Hsp90 complex about three times [88].

\section{Coumarins}

$\nabla$

Since 2000, when the fungal aminocoumarins novobiocin was identified as a new type of Hsp90 inhibitor acting with a mechanism clearly different from that of classical anti-ATPase inhibitors such as GDA and radicicol [89], plant coumarins were screened in order to identify further Hsp90 modulators. However, such a large effort produced poor results, and actually only one plant coumarin can be undoubtedly considered an Hsp90 inhibitor: GUT-70. It is a tricyclic coumarin extracted from the stem bark of Calophyllum brasiliense Britton (Calophyllaceae) showing significant and specific cytotoxicity towards human leukemic cells [90] and proapoptotic effects on mantle cell lymphoma cell lines. These anticancer activities can be, almost partially, ascribed to GUT-70's ability to interact with Hsp90, as inferred by specific competition studies, and to induce intracellular level reductions for some Hp90 client proteins, such mt-p53, Raf-1, cyclin D1, and Akt [91].

The only other report on plant isolated coumarin interaction with Hsp90 is the $K_{\mathrm{D}}(\sim 0.20 \mu \mathrm{M})$ of the dicoumarinyl ether glycosideHsp90 interaction obtained through SPR analysis by Malafronte et al. in 2012. This result was expected on the basis of the wellknow affinity of novobiocin and its derivatives towards Hsp90 [88].

\section{Anthraquinones \\ $\nabla$}

Anthraquinones are well known for their action on the gastrointestinal system and for their estrogenic activities. However, some interesting findings have been reported also on the antiproliferative and antiangiogenic effects, which could be related to Hsp90 inhibition [92]. Aloe-emodin, a natural anthraquinone purified from different aloe latex, was shown to have antiproliferative effects on breast cancer cell proliferation by downregulating ER $\alpha$ protein levels. This downregulation was due to the inhibition of interaction of ER with Hsp90, leading to a significant increase of ER ubiquitination and proteasomal degradation [93]. Interestingly, the related compound emodin had no effect on Hsp90/ER binding. On the other hand, the semisynthetic derivative emodin azide methyl anthraquinone strongly inhibits the interaction of Hsp90 with several client proteins. In particular, it induces proteasomal degradation of the Her2/neu protein, a transmembrane tyrosine kinase well known to be associated with a poor prognosis in breast cancer, preventing its interaction with Hsp90 [94].

Also rhein, the primary anthraquinone in the roots of Cassia alata L. (Fabaceae), was described as a promising antitumoral agent, but its effect seems to be mainly related to the inhibition of tumor-induced angiogenesis by suppressing the activation of PI3K, p-Akt, and phosphorylated extracellular signal-regulated kinase.
However, an in-depth investigation on its mechanism of action in breast cancer cell lines revealed that rhein induces proteosomal degradation of some Hsp90 client proteins, such as NF-kB and Her-2, thus suggesting this anthraquinone as a direct inhibitor of Hsp90 [95].

\section{Tannins}

$\nabla$

The ellagitannin geraniin, firstly isolated from the Japanese medicinal plant Geranium thunbergii Siebold ex Lindl. \& Paxton (Geraniaceae), has emerged from an SPR-based screening of a small library, including different plant polyphenols, as an efficient ligand of $\mathrm{Hsp} 90\left(K_{\mathrm{D}} 415 \pm 2.70 \mathrm{nM}\right)$ [96]. On the basis of this first evidence, the authors carried out several biological and biochemical assays, demonstrating that geraniin dose-dependently inhibits ATPase and chaperone activities of Hsp90. Moreover, the level of the client proteins c-Raf, pAkt, and EGFR was strongly downregulated in two cancer cell lines (HeLa and Jurkat) treated with different doses of geraniin (from 0.5 to $10 \mu \mathrm{M}$ ). Preliminary, a structural investigation performed on the Hsp90/geraniin complex suggested the $\mathrm{N}$-terminal region of the protein to be involved in geraniin binding [96]. Geraniin has been shown by different authors to possess several biological activities: it suppresses A549 cancer cells proliferation, arresting the cell cycle in the $S$ phase [97], negatively modulates the expression of carbonic anhydrase II mRNA in osteoclasts $[98,99]$, attenuates radiationinduced damage in mice splenocytes by reducing DNA breakage and apoptosis [100], and inhibits human enterovirus 71 replication [101]. Interestingly, most of these activities could depend on geraniin's ability to inhibit Hsp90 function. However, the biological effects of tannins usually depend on their grade of polymerization and solubility. Highly polymerized tannins exhibit low bioaccessibility in the small intestine and low fermentability by colonic microflora. Therefore, the low bioavailability of this class of compounds should be considered [102].

\section{Terpenes \\ $\nabla$}

\section{Monoterpenes}

Picrocrocin is a monoterpene glycoside constituent of saffron (Crocus sativus L., Iridaceae) stigmas, and it's a precursor of safranal. In a study to attempt the identification of the antitumor therapeutic target of saffron, picrocrocin was subjected to a comparative analysis based on two different reverse screening approaches, i.e., reverse docking system based on an id Target and the reverse pharmacophore mapping strategy based on a PharmMapper system. Results suggested that picrocrocin acts as a competitive inhibitor in the ATPase site of $\mathrm{Hsp} 90 \alpha$, revealing that an electrostatic interaction and hydrogen bonds facilitate the binding of the molecule in the ATPase catalytic site of the enzyme and can possibly act as a competitive inhibitor and a potential antitumor drug [103].

\section{Iridoids}

In a target-oriented screening on a plant molecule library for putative Hsp90 inhibitors, the class of iridoids was selected as one chemical scaffold. Iridoids, secoiridoids, and $\mathrm{C}_{9}$-type iridoids were screened, and only the latter showed a promising inhibitory activity. These results motivated the authors to isolate $\mathrm{C}_{9}$-type iridoids from two plants belonging to the Bignoniaceae family, 
Tabebuia argentea Britt. and Catalpa bignonioides Walter. A SPRbased binding assay was performed to study the binding of $\mathrm{C}_{9}$ type isolated iridoids to Hsp90. Four monomers, catalposide, specioside, 3,4-dihydrocatalposide, and 6- 0 -p-hydroxybenzoyl-5,7bisdeoxycynanchoside, and two dimers, named argenteoside $\mathrm{A}$ and $B$, were demonstrated to bind the chaperone [104]. Argenteoside A and B showed a good affinity towards Hsp90, having $K_{\mathrm{D}}$ values measured for the interaction with the chaperone of $K_{\mathrm{D}}$ $14 \pm 4.00 \mathrm{nM}$ and $50 \pm 9.00 \mathrm{nM}$, respectively, comparable to that of radicicol (4.20 nM), used as a reference compound. Moreover, these compounds showed a kinetic dissociation constant $\left(k_{d}\right)$ notably lower than those measured for the monomers, indicating that the Hsp90/dimeric iridoids complexes were extremely stable. Thus, a panel of chemical and biological approaches was used to characterize the most active iridoid argenteoside A inhibitory activity. ATPase assay, citrate synthase aggregation assay, and cell-based studies were carried out to deepen the study of the interaction between argenteoside A and the enzyme, suggesting that it efficiently inhibited Hsp90 ATPase and chaperone activity, downregulating Hsp90 $\alpha$ client proteins without inducing any increase in Hsp70 levels. The structural characterization of the Hsp90-argenteoside A complex was obtained by limited proteolysis mass spectrometry-based strategy analysis using trypsin and chemotrypsin as proteolytic probes. A comparison between the cleavage sites of Hsp90 and the Hsp90-argenteoside A complex demonstrated that the $\mathrm{N}$-terminal domain and a middle domain of the chaperone were involved in the molecule binding. To obtain more details about a possible binding mode of argenteoside A on Hsp90, a molecular modeling analysis was also performed. Achieved results were refined taking into account the limited proteolysis experimental data. This last study supported the view that argenteoside A interacts with the $\mathrm{N}$-terminal domain as disclosed by limited proteolysis analysis. $\mathrm{C}_{9}$-types iridoids may be considered a new promising chemical scaffold for an Hsp90 inhibitors drug discovery program [104].

Recently, oleocanthal, an olive oil phenolic component, has attracted increasing interest for its biological effects. This molecule was reported to interfere with a number of pathways related to inflammation and Alzheimer's disease [105]. Margarucci and coauthors, to obtain a comprehensive identification of oleocanthal interactome, applied a mass spectrometry proteomic approach. The study of oleocanthal putative partner in HeLa and U937 cell lysates revealed Hsp90 as a unique shared target. Oleocanthal was found to strongly inhibit the Hsp90 ATPase activity in a concentration-dependent manner, similar to radicicol. A molecular docking analysis suggested a potential covalent reactivity between the compound and the chaperone. This interaction was also analyzed by detailed MS analysis. The authors suggested that the correct positioning of oleocanthal in the Hsp90 binding site was induced by van der Waals and hydrophobic interactions, and is followed by covalent modifications at Lys112 and Lys58. Moreover, oleocanthal influenced the Hsp90 oligomeric state by inducing a chaperone conformational change with no covalent oleocanthal cross-linked species between Hsp90 monomers. Anyway, oleocanthal did not influence the regulation of Hsp90 and Hsp70 [106].

\section{Sesquiterpenes}

Among sesquiterpenes, terpenes with a $C_{15}$ carbon atom skeleton, two compounds isolated from plants of the Zingiberaceae family, were found to interact with Hps90. $\beta$-Elemene is an active component of the medicinal plant Curcuma wenyujin Y.H. Chen
\& C. Ling (Zingiberaceae) and antagonizes glioblastoma cells by inducing apoptosis. Zhao et al. found that $\beta$-elemene disrupted the Hsp90/Raf-1 complex, hypothesizing that an alkylating agent could antagonize the molecular chaperone function of Hsp90 (that is dependent on its conserved spatial conformation), causing its misfolding and unbinding to Raf-1 [107]. Deactivation of Raf-1 consequently inhibited the Raf/MEK/ERK pathway, leading to apoptosis of glioblastoma cells.

Zerumbone, isolated from Zingiber zerumbet Smith (Zingiberaceae), was reported to exert many bioactivities such as cancer preventive, anti-inflammatory, and detoxifying actions. Ohnishi et al. studying zerumbone's possible mechanism of action in hepa1c1c7 mouse hepatoma cells found that this compound bound to proteins through its $\alpha, \beta$-unsaturated carbonyl group. The authors hypothesized that zerumbone-modified proteins were recognized by Hsp90 for heat shock response induction [108].

\section{Diterpenes}

Andrographolide, 14-deoxy-11,12-didehydroandrographolide, and neoandrographolide are the major labdane diterpenoids isolated from Andrographis paniculata (Burm.f.) Wall ex Nees, an herbaceous plant belonging to the Acanthaceae family, that have exhibited a variety of pharmacological activities [109]. Andrographolide possesses interesting in vitro and in vivo anti-inflammatory (asthma, stroke, and arthritis) and anticancer effects [110, 111]. Indeed, it suppresses the secretion of cytokines, chemokines, and inflammatory enzymes (iNOS and COX) from macrophages [112]. In these years, many studies have reported andrographolide as a very promising compound for cancer treatment, and several molecular mechanisms and potential molecular targets have been proposed for its antitumor effect [111]. A number of reports showed that andrographolide and its analogues induced cell cycle arrest and promoted apoptosis in human cancer cells by interfering with various cell signaling pathways. In a recent study, Liang and coworkers demonstrated that this natural compound suppresses viral sarcoma-induced epithelial cellular transformation by promoting viral sarcoma protein degradation [113]. These findings provide evidence that andrographolide exerts its anticancer action by a novel mechanism involving the degradation of sarcoma oncoprotein. In 2014, to further investigate its biological activity, using proteomics and Western blot approaches, they proposed a novel mechanism for the suppression of cancer cell malignancy induced by andrographolide through the inhibition of the Hsp90 chaperone machinery and depletion of Hsp90-dependent client proteins. Finally, a treatment with andrographolide induced Hsp90 cleavage, downregulated the client protein Bcr-Abl, and inducted apoptosis in K562 cells [114].

Teucrin A, a furan-containing diterpenoid, is a major constituent of the neo-clerodane diterpenoid fraction of the hydroalcoholic extract of germander (Teucrium chamaedrys L., Lamiaceae). Among the broad range of protein targets affected by teucrin A treatment in the rat liver, the cytosolic Hsp90 was found as a target of the activated diterpenoid [115].

Rosmarinic acid, carnosic acid, and carnosol are the three major bioactive constituents in rosemary leaves (Rosmarinus officinalis, L. Lamiaceae) responsible for the antioxidant, anti-inflammatory, and anticancer properties. Carnosol is contained in zyflamend, a commonly used dietary supplement that contains extracts of ten common herbs including rosemary (R. officinalis), turmeric (Curcuma longa L., Zingiberaceae), ginger (Zingiber officinale Roscoe, Zingiberaceae), holy basil (Ocimum sanctum L., Lamiaceae), green tea (C. sinensis), hu zhang (Polygonum cuspidatum Sieb. \& Zucc., 
Polygonaceae; a source of resveratrol), Chinese goldthread (Coptis chinensis Franch., Ranunculaceae), barberry (Berberis vulgaris L., Berberidaceae), oregano (Origanum vulgare L., Lamiaceae), and baikal skullcap (Scutellaria baicalensis Georgi, Lamiaceae). The inhibition of Hsp90 ATPase activity induced by carnosol and zyflamend has been reported [116]. In this study, both carnosol and zyflamend inhibited Hsp90 function leading to a rapid reduction in AhR levels, an Hsp90 client protein that is strongly involved in PAH-induced carcinogenesis. Tobacco smoke, a source of PAHs, activates the AhR, leading to the improved transcription of CYP1A1 and CYP1B1, which encode proteins that convert PAHs to genotoxic metabolites. Through the inhibition of Hsp90 ATPase activity, carnosol induces a decrease in AhR protein levels, suppresses PAH-mediated activation of CYP1A1 and CYP1B1, and represses mutagenesis $[116,117]$. These results suggest that the antitumor effects of rosemary herbs may be attributed to the inhibition of Hsp90 mediated by carnosol.

The bioactive diterpene tanshinone IIA, isolated from Salvia miltiorrhiza Bunge (Lamiaceae), has been used in the treatment of cardiovascular and metabolic disorders [118]. eNOS uncoupling plays a causal role in endothelial dysfunction in many cardiovascular and metabolic diseases, and it was found that this natural product acts by interacting with the NO pathway. Recently, a study addressed to investigate its role in oxidative stress-related signaling disclosed the effect of tanshinone IIA on the expression of Hsp90 [118].

\section{Limonoids}

Gedunin, a tetranortritepenoid (limonoid) isolated from Indian neem (Azadirachta indica A. Juss., Meliaceae), is well known for its antimalarial and insecticidal activities, and has demonstrated anticancer activity. This activity was firstly explored through the use of the gene expression signatures, a method applied to connect small molecules, genes, and diseases. With this technique, Lamb et al., in 2006, found that gedunin exhibited its antiproliferative activity through Hsp90 modulation [119]. Later, the same authors found that gedunin inhibited androgen receptor-mediated signaling and a gene expression-based approach was used to predict that it acts as an Hsp90 pathway inhibitor [120]. At that time, the only known mechanism of action of Hsp90 inhibitors was the one demonstrated for 17-AAG and GDA at the $\mathrm{N}$-terminal ATP-binding pocket, while a new mechanism outside the $\mathrm{N}$-terminal was proposed for gedunin. In fact, this tetranortriterpene was found to promote the Hsp90-dependent client protein similarly to other Hsp90 inhibitors, while, contrary to the other inhibitors, it was unable to displace GDA in a fluorescence polarization assay with Hsp90. In an effort to probe gedunin's mechanism of action, 19 semisynthetic derivatives were prepared and their antiproliferative activity was determined. No compound was found to be more effective than the natural compound [121] and gedunin could be considered an Hsp90 inhibitor that didn't interact directly with the chaperone.

Taking into account Hsp90-gedunin inhibitor activity and that limonoids are a relatively small group of tetranorterpenoids typical of Meliaceae, Dal Piaz et al. started a phytochemical investigation of plants belonging to this family. Extraction and chromatographic separation of Trichilia emetica ssp. suberosa JJ de Wilde and Pseudrocedrela kotschyi (Schweinf.) Harms root extracts led to the isolation of 16 compounds. Two phragmalin limonoids, kotschyin A and kotschyin D from P. kotschyi, interacted with the immobilized protein by an SPR study. Among them, kotschyin D exhibited a $K_{\mathrm{D}}$ of $0.36 \pm 0.04 \mu \mathrm{M}$, comparable to that measured for
17 -DMAG $\left(K_{\mathrm{D}} 0.39 \pm 0.07 \mu \mathrm{M}\right)$. Combining limited proteolysis and molecular docking with biochemical and cellular studies, kotschyin $\mathrm{D}$ was demonstrated to be a client-selective inhibitor of the chaperone, binding to the Hsp90 middle domain. Moreover, observations on the effects of cell incubation with kotschyin D on the level of different Hsp90 clients inferred the hypothesis that this molecule reduces the efficiency of the chaperone towards specific client proteins by preventing its interaction with the cochaperone Aha1 [122].

Recently, the same authors isolated 14 limonoids from A. indica leaves collected in Venezuela. An SPR-based study was used to study the interaction between these limonoids and Hsp90. Among them, deacetylsalannin and 1,3-diacetylvilasinin showed a capability to bind Hsp90 with an affinity higher than that obtained for the 17-AAG. The results obtained showed that the Hsp90 inhibitory effect of these limonoids is strongly related to different structural features of the side chains [123].

\section{Triterpenes}

The quinone methide triterpene CL belongs to a small category of plant secondary metabolites that possess a broad range of biological activity. It was isolated from Tripterygium wilfordii Hook. f. (Celastraceae) root extract (Thunder God Vine), a remedy used for inflammatory and autoimmune diseases in Oriental traditional medicine [124]. Different evidences showed that in the CL structure, carbons C-2 and C-6 on the A and Bring, respectively, exert a high susceptibility towards a nucleophilic attack, forming Michael adducts with nucleophilic groups of proteins. Analogously to many plant molecules, this property seems to be the major mechanism by which CL modulates the activity of a variety of proteins [125]. Over recent years, CL has attracted many researchers attention through its diverse biological activities [126-131]. Hieronymus and coauthors, in order to investigate the molecular target of $\mathrm{CL}$, applied a gene-based expression analysis to connect its activities to other known drugs, demonstrating that it inhibits Hsp90 functions [120]. Several investigations on the effects of CL-Hsp90 interaction have been successively performed. The effect of CL on many Hsp90 clients, including some kinases, was confirmed in many cancer cell line studies by different authors, reporting the downregulation of Hsp90 clients such as Akt-1, NF-kB, Raf-1, Cdks, ERK, EGFR, FceRI, and PKC $\delta$ [131137]. Zhang and coworkers studied the effect of CL on different transcription factors, one being the subpopulation of Hsp90 clients, in three human cancer cell lines (MCF7, HepG2, THP-1), observing the protein levels and showing that this compound affects many nuclear factors in a cell-type and dose-dependent way. CL showed a capability of blocking the binding of Hsp90 and its co-chaperones (Cdc37, P23, Hop), resulting in antitumoral activity $[125,138,139]$. The molecular mechanism of the CL-Hsp90 interaction has been extensively investigated. Zhang et al. studied the effect of CL on the Hsp90 interaction and ATPase inhibition, suggesting that it binds to the $N$-terminal domain, and that this is the site of Cdc37 and ATP binding $[138,140]$. On the other hand, trypsinolysis studies suggested that CL binds to the $C$-terminal domain of the chaperone. Some studies have reported the inhibition of Hsp90 ATPase activity [131], while others demonstrated that $\mathrm{CL}$ does not affect the ATPase activity of the chaperone $[138,141]$. Other authors demonstrated that CL disrupts the Hsp90/Hop complex [142], but others stated that it has no effect on Hop [138]. Recently, Zanphorlin and coworkers, based on these conflictual evidences, performed a characterization of the CL-Hsp90 interaction using both biochemical and biophysical 
techniques [143]. These authors suggested a model in which CL binds to the $\mathrm{C}$-terminal domain, causing oligomerization of the chaperone. CL may act primarily by inducing specific oligomerization that inhibits some, but not all, of the Hsp90 functions. Definitively, the characterization of the CL-Hsp90 molecular interaction needs further studies.

In a study focused on the observation of protein changes caused by betulin, a representative triterpene of Betula platyphylla Sukaczev (Betulaceae), Pyo et al. demonstrated that Hsp90 was downregulated in betulin-treated human lung cancer A549 cells. They also confirmed that betulin induced apoptosis by up/downregulations of different proteins by means of 2DSDS PAGE coupled with nano-HPLC tandem mass spectrometry [144].

Triterpenes have been identified as the major active constituents of Patrinia heterophylla Bunge (Valerianaceae), a native herb to China used as an antitumor herb in traditional Chinese medicine. To elucidate the antitumor mechanism of these compounds, a proteomic analysis was carried out by TPH treatment in K562 cells. According to their previous phytochemical analysis, hederagenin, friedelin, ursolic acid, oleanolic acid, canophyllol, oleanolic acid 3-O- $\alpha$-L-arabinopyranoside, $\alpha$-amyrin, and $\beta$-amyrin are the main components of TPH [145]. The authors found that TPH downregulated the expression of Hsp90 $\alpha$ in K562 cells, so triterpenes could be responsible of this activity, but further investigations are needed to explain these evidences [146].

\section{Alkaloids}

The wide range of biological activities shown by alkaloids encouraged researchers to evaluate their effects on Hsp90 activity and/or expression in tumor cells in order to identify new potent and multitarget compounds. Promising results have been achieved by some bis-coclaurine alkaloids such as CEP and BBM. Using different chromatographic approaches, Haginaka and coworkers [147] demonstrated that CEP, an alkaloid mainly extracted from Stephania cepharantha Hayata (Menispermaceae) and widely used in Japan to treat several diseases [148], interacts with the Hsp90 middle domain, and a $5.3 \mu \mathrm{M}$ dissociation constant was measured for this interaction. These authors also obtained a similar result investigating the Hsp90 interaction with BBM, purified from several plants belonging to the Berberis genus (Berberidaceae), and reported it as promising anticancer agent [149-152]. Moreover, it was also demonstrated that BBM treatments induce leukemia cell apoptosis, interfering with different metabolic pathways and significantly reducing the Hsp90 intracellular levels [153].

An efficient interaction with the Hsp90 middle domain was also observed for lentiginosine [154], a hydroxylated indolizidine alkaloid originally extracted from the leaves of Astragalus lentiginosus Douglas ex Hook (Fabaceae) and described as a potent inhibitor of the fungal $\alpha$-glucosidase amyloglucosidase [155]. A multidisciplinary study demonstrated that the binding of this iminosugar to the chaperone is enantioselective, with only the (+)-lentiginosine being able to interact with Hsp90 with a high affinity $\left(K_{\mathrm{D}}=24.76 \pm 0.60 \mathrm{nM}\right)$; besides, it was able to significantly affect chaperone and ATPase activities of the protein in vitro [154].

\section{Miscellaneous}

Gambogic acid, a component of the exudate of Garcinia harburyi Hook. f. (Clusiaceae), has been demonstrated to possess antitumor and anti-inflammatory activities and has entered phase I clinical trials in China as an anticancer agent [156]. This compound was firstly shown to interact with Hsp90 in 2010. In fact, gambogic acid inhibits HeLa cell proliferation with an $\mathrm{IC}_{50}$ of $0.69 \pm 0.22 \mu \mathrm{M}$, which correlates with the downregulatation of the TNF- $\alpha / N F-k B$ signaling pathway [157]. Later, a high-throughput screening of a natural product library for the discovery of new Hsp90 inhibitors identified gambogic acid as an antitumor agent that binds to the $\mathrm{N}$-terminal domain of Hsp90 [158]. In this study, gambogic acid emerged for its ability to inhibit the Hsp90dependent refolding of luciferase. Biological assays on gambogic acid displayed its ability to inhibit the proliferation of different cancer cell lines (HeLa, MCF7, and SK-Br3) in a concentration-dependent manner, and induced degradation of Hsp90-dependent proteins Her2, Akt, and Raf-1 in cultured cells [158]. This promising anticancer agent also disrupted the interaction of Hsp90, Hsp70, and Cdc 37 with the HRI in vitro. In addition, by SPR analysis and virtual docking approaches, Davenport and coworkers indicated that gambogic acid binds to the $\mathrm{N}$-terminal domain of Hsp90, and it is not able to displace GDA, suggesting its interaction with a distinct binding site on the Hsp90 $\mathrm{N}$-terminal pocket [158].

\section{Conclusions \\ $\nabla$}

In this review, plant molecules interfering with Hsp90 activities ( Table 1) and outlining findings on their molecular interaction with the chaperone are presented. The identification of new compounds to modulate Hsp90 activities is still a crucial challenge for biomedical research. In the last ten years, many putative Hsp90 inhibitors have been reported, including natural compounds, but actually only a limited number of plant secondary metabolites showing promising effects have been described. However, many of these plant compounds inhibit Hsp90 by mechanisms definitively different from those demonstrated for the classic inhibitors interacting with the Hsp90 ATP binding site; this is the case of the prenylated isoflavone derrubone, the terpenoids kotshin D and CL, and the alkaloids CEP and lentiginosine. In fact, the first is able to over-stabilize the binding between the chaperone and some of its clients, the second prevent the interaction of Hsp90 with its co-chaperones Aha1 (kotshin D), Cdc37, P23, and Hop (CL), while the third bind the Hsp90 middle domain, thus affecting its interaction with several client proteins, respectively. The peculiarity of the mechanism of action demonstrated by these compounds makes them suitable leads for the design of new therapeutic agents, or chemical probes allowing for the in-depth study of the biochemistry of Hsp90, a chaperone machine which plays a key role in many pathological and physiological processes.

\section{Conflict of Interest \\ $\nabla$}

The authors declare no conflict of interest. 
Table 1 Plant secondary metabolites interfering with Hsp90 activities.

Compound Aloe-emodin Structure

Andrographolide



Apigenin

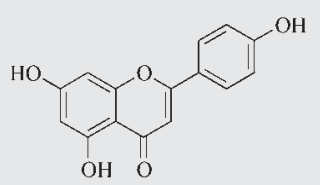

Argenteoside A



Argenteoside B

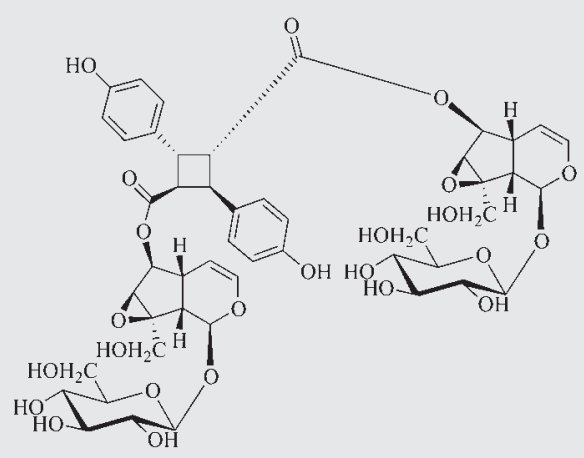

Berbamine

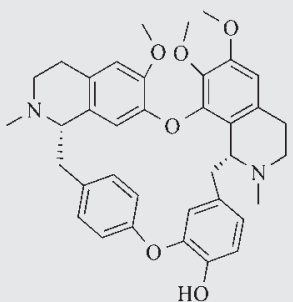

Betulin

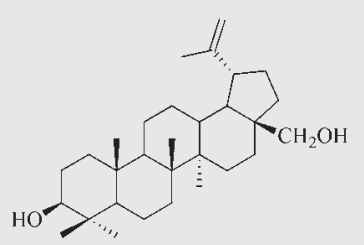

\section{Origin}

Aloe vera (L.) Burm. f. (Aloaceae)

References

$[93,94]$

Andrographis paniculata (Burm. F.)

Wall. Ex Nees (Acanthaceae)

[109-114]

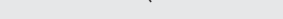

Asteraceae family

[14-19]

Tabebuia argentea Britt.

(Bignoniaceae)

Tabebuia argentea Britt.

(Bignoniaceae)

[104]

Berberis ssp. (Berberidaceae)

[149-153]

Betula platyphylla Sukaczev

(Betulaceae)

[144] 
Table 1 Continued

\section{Compound}

Butein<smiles>O=C(/C=C/c1ccc(O)c(O)c1)c1ccc(O)cc1O</smiles>

Carnosol<smiles>CC(C)c1cc2c(c(O)c1O)C13CCCC(C)(C)C1CC(C3)OC2=O</smiles>

\section{Catalposide}

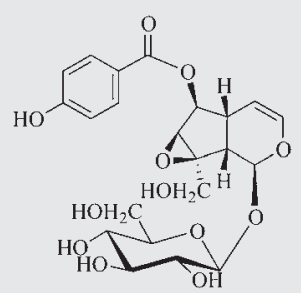

Celastrol

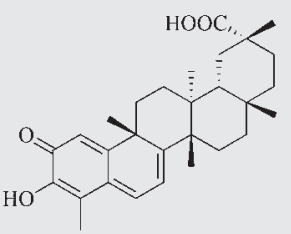

Cepharanthine<smiles>COc1cc2c(cc1Oc1c(OC)cc3c(c1Oc1cc(C)ccc1Oc1ccc(C)cc1)CN(C)CC3)C[C@H](C)N(C)CC2</smiles>

Chrysin<smiles>O=c1cc(-c2ccccc2)oc2cc(O)cc(O)c12</smiles>

Deacetylsalannin

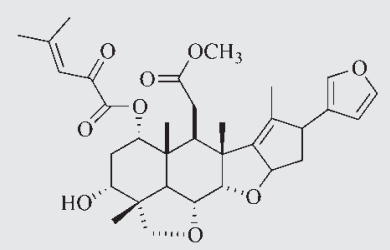

Derrubone<smiles>CC(C)=CCc1c(O)cc2occ(-c3ccc4c(c3)OCO4)c(=O)c2c1O</smiles>

1,3-Diacetylvilasinin

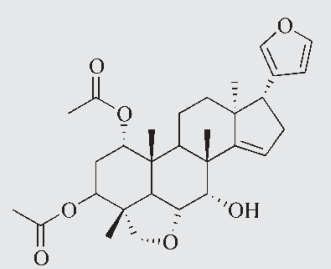

Origin

Semecarpus anacardium L., Caragana jubata Pall., Rhus verniciflua Stokes (Anacardiaceae), Dalbergia odorifera T. Chen (Fabaceae)

Rosmarinus officinalis L. (Lamiaceae)

Tabebuia argentea Britt. (Bignoniaceae)

Tripterygium wilfordii Hook.f. (Celastraceae)

[124-143]

Stephania cepharantha Hayata (Menispermaceae)

$[147,148]$

eferences

[55-64]

Derris robusta (Roxb ex DC) Benth

[47-54] (Fabaceae)

Azadirachta indica A. Juss. (Meliaceae)

[123] 
Table 1 Continued

\section{Compound}

3,4-Dihydrocatalposide

17-DMAG

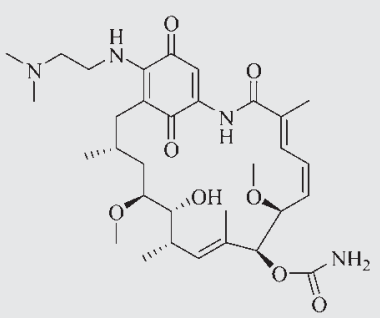

$\beta$-Elemene<smiles>C=C[C@H]1CCC(C(=C)C)CC1C(=C)C</smiles>

(-)-Epicatechin<smiles>Oc1cc(O)c2c(c1)O[C@H](c1ccc(O)c(O)c1)C(O)C2</smiles>

(-)-Epigallocatechin-3-gallate<smiles>O=C(O[C@H]1Cc2c(O)cc(O)cc2O[C@H]1c1ccc(O)c(O)c1)c1cc(O)c(O)c(O)c1</smiles>

Eupatilin<smiles>COc1ccc(-c2cc(=O)c3c(O)c(OC)c(O)cc3o2)cc1OC</smiles>

Flavokawain B<smiles>COc1cc(O)c(C(=O)/C=C/c2ccccc2)c(OC)c1</smiles>

Gambogic acid



Gedunin

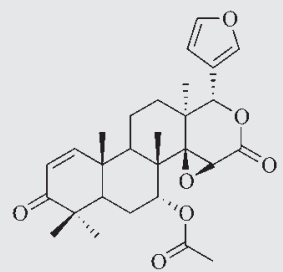

\section{Origin}

Catalpa bignonioides Walter (Bignoniaceae)

References

[104]

Semisynthetic derivative

Curcuma wenyujin Y.H. Chen \& C. Ling (Zingiberaceae)

[107]

Camellia sinensis (L.) Kuntze (Theaceae)

Camellia sinensis (L.) Kuntze (Theaceae)

[54,79-85]

Artemisia asiatica Nakai (Asteraceae)

$[26,27]$

Piper methisticum (L.) G. Forst

[65-73] (Piperaceae), Alpinia pricei Hayata (Zingiberaceae)

Garcinia harburyi Hook.f. (Clusiaceae)

[156-158]

Azadirachta indica A. Juss. (Meliaceae)

[119-121] 
Table 1 Continued

\section{Compound}

GDA



Geraniin

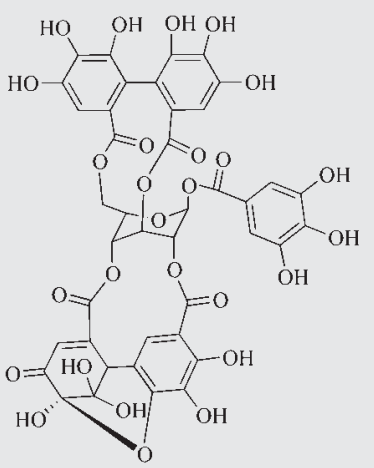

GUT-70

6-O-p-Hydroxybenzoyl-5,7-

bisdeoxycynanchoside



2"-Hydroxygenkwanol A



Kotschyin A

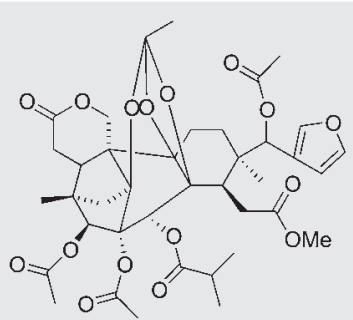

Origin

Streptomyces hygroscopicus

References

$[12,13]$

Geranium thunbergii Siebold ex Lindl.

\& Paxton (Geraniaceae)

[96-102]

Calophyllum brasiliense Britton

$[90,91]$

(Calophyllaceae)

[104]

Catalpa bignonioides Walter

(Bignoniaceae)

Daphne linearifolia (Hart.)

(Thymelaeaceae)

Pseudrocedrela kotschyi (Schweinf)

[122] 
Table 1 Continued

\section{Compound}

Kotschyin D

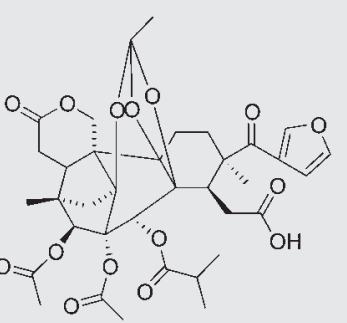

Lentiginosine<smiles>OC1CN2CCCCC2C1O</smiles>

Licochalchone A<smiles>C=CC(C)(C)c1cc(/C=C/C(=O)c2ccc(O)cc2)c(O)cc1OC</smiles>

Luteolin<smiles>O=c1cc(-c2ccc(O)c(O)c2)oc2cc(O)cc(O)c12</smiles>

Novobiocin<smiles>COC1[C@@H](OC(N)=O)[C@@H](O)C(Oc2ccc3c(O)c(NC(=O)c4ccc(O)c(CC=C(C)C)c4)c(=O)oc3c2C)OC1(C)C</smiles>

Oleocanthal<smiles>C/C=C(/C=O)C(CC=O)CC(=O)OCCc1ccc(O)cc1</smiles>

Picrocrocin

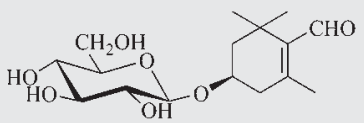

Quercetin<smiles>O=c1c(O)c(-c2ccc(O)c(O)c2)oc2cc(O)cc(O)c12</smiles>

Radicicol<smiles>CO[C@H](C)CC/C=C\C=C/C(=O)Cc1c(Cl)c(O)cc(O)c1C(=O)O</smiles>

Rhein<smiles>O=C(O)c1cc(O)c2c(c1)C(=O)c1cccc(O)c1C2=O</smiles>

Origin

Pseudrocedrela kotschyi (Schweinf)

Harms (Meliaceae)

Astragalus lentiginosus Douglas ex Hook. (Fabaceae)

Glycyrrhiza inflate Batalin (Fabaceae)

[74-78]

Many plants and vegetables

[28-35]

Streptomyces niveus

Olea europaea L. (Oleaceae)

$[105,106]$

Crocus sativus L. (Iridaceae)

[103]

Many plants and vegetables

[36-46]

Penicillium luteo-aurantium

Cassia alata L. (Fabaceae)
[89]

[95]

References

[122]

$[154,155]$ 
Table 1 Continued

\begin{tabular}{|c|c|c|c|}
\hline Compound & Structure & Origin & References \\
\hline Specioside & & $\begin{array}{l}\text { Tabebuia argentea Britt. } \\
\text { (Bignoniaceae) }\end{array}$ & [104] \\
\hline Tanshinone II A & 0 & Salvia miltiorrhiza Bunge (Lamiaceae) & [118] \\
\hline Teucrin A & & Teucrium chamaedrys L. (Lamiaceae) & [115] \\
\hline Zerumbone & & $\begin{array}{l}\text { Zingiber zerumbet Smith } \\
\text { (Zingiberaceae) }\end{array}$ & [108] \\
\hline
\end{tabular}

\section{References}

1 Zhang $H$, Burrows $F$. Targeting multiple signal transduction pathways through inhibition of Hsp90. J Mol Med 2004; 82: 488-499

2 Whitesell L, Lindquist SL. Hsp90 and the chaperoning of cancer. Nat Rev Cancer 2005; 5: 761-772

3 Pearl LH, Prodromou C. Structure and in vivo function of Hsp90. Curr Opin Struct Biol 2000; 10: 46-51

4 Patki JM, Pawar SS. Hsp90: chaperone-me-not. Pathol Oncol Res 2013; 19: $631-640$

5 Scheibel T, Buchner J. The Hsp90 complex-a super-chaperone machine as a novel drug target. Biochem Pharmacol 1998; 56: 675-682

6 Solit DB, Rosen N. Hsp90: a novel target for cancer therapy. Curr Top Med Chem 2006; 6: 1205-1214

7 Holzbeierlein JM, Windsperger A, Vielhauer G. Hsp90: a drug target? Curr Oncol Rep 2010; 12: 95-101

8 Jego G, Hazoume A, Seigneuric R, Garrido C. Targeting heat shock proteins in cancer. Cancer Lett 2013; 332: 275-285

9 Neckers L, Workman P. Hsp90 molecular chaperone inhibitors: are we there yet? Clin Cancer Res 2012; 18: 64-76

10 Bhat R, Tummalapalli SR, Rotella DP. Progress in the discovery and development of heat shock protein 90 (Hsp90) inhibitors. J Med Chem 2014; 57: 8718-8728

11 Carlson EE. Natural products as chemical probes. ACS Chem Biol 2010; 5: 639-653

12 Neckers L. Chaperoning oncogenes: Hsp90 as a target of geldanamycin. Handb Exp Pharmacol 2006; 172: 259-277

13 Jhaveri K, Ochiana SO, Dunphy MP, Gerecitano JF, Corben AD, Peter RI, Janjigian YY, Gomes-DaGama EM, Koren 3rd J, Modi S, Chiosis G. Heat shock protein 90 inhibitors in the treatment of cancer: current status and future directions. Expert Opin Investig Drugs 2014; 23: 611-628

14 Patel D, Shukla S, Gupta S. Apigenin and cancer chemoprevention: progress, potential and promise (review). Int J Oncol 2007; 30: 233-245

15 Shukla S, Gupta S. Apigenin: a promising molecule for cancer prevention. Pharm Res 2010; 27: 962-978
16 Simons AL, Renouf M, Hendrich S, Murphy PA. Human gut microbial degradation of flavonoids: structure-function relationships. J Agric Food Chem 2005; 53: 4258-4263

17 Tang $D, Y u$ Y, Zheng X, Wu J, Li Y, Wu X, Du Q Yin X. Comparative investigation of in vitro biotransformation of 14 components in Ginkgo bilo$b a$ extract in normal, diabetes and diabetic nephropathy rat intestinal bacteria matrix. J Pharm Biomed Anal 2014; 100: 1-10

18 Osada M, Imaoka S, Funae Y. Apigenin suppresses the expression of VEGF, an important factor for angiogenesis, in endothelial cells via degradation of HIF-1 $\alpha$ protein. FEBS Lett 2004; 575: 59-63

19 Zhao M, Ma J, Zhu HY, Zhang XH, Du ZY, Xu YJ, Yu XD. Apigenin inhibits proliferation and induces apoptosis in human multiple myeloma cells through targeting the trinity of CK2, Cdc37 and Hsp90. Mol Cancer 2011; 10: 104

20 Miski M, Ulubelen A, Johansson C, Mabry TJ. Antibacterial activity studies of flavonoids from Salvia palaestina. J Nat Prod 1983; 46: 874-875

21 Wolfman C, Viola H, Paladini A, Dajas F, Medina JH. Possible anxiolytic effects of chrysin, a central benzodiazepine receptor ligand isolated from Passiflora coerulea. Pharmacol Biochem Behav 1994; 47: 1-4

22 Brown E, Hurd NS, McCall S, Ceremuga TE. Evaluation of the anxiolytic effects of chrysin, a Passiflora incarnata extract, in the laboratory rat. AANA J 2007; 75: 333-337

23 Lapidot T, Walker MD, Kanner J. Antioxidant and prooxidant effects of phenolics on pancreatic $\beta$-cells in vitro. J Agric Food Chem 2002; 50: 7220-7250

24 Cho H, Yun CW, Park WK, Kong JY, Kim KS, Park Y, Lee S, Kim BK. Modulation of the activity of pro-inflammatory enzymes, COX-2 and iNOS, by chrysin derivatives. Pharmacol Res 2004; 49: 37-43

25 Fu B, Xue J, Li Z, Shi X, Jiang BH, Fang J. Chrysin inhibits expression of hypoxia-inducible factor- $1 \alpha$ through reducing hypoxia-inducible factor- $1 \alpha$ stability and inhibiting its protein synthesis. Mol Cancer Ther 2007; 6: 220-226

26 Seo HJ, Surh YJ. Eupatilin, a pharmacologically active flavone derived from Artemisia plants, induces apoptosis in human promyelocytic leukemia cells. Mutat Res 2001; 496: 191-198 
27 Kim JM, Lee DH, Kim JS, Lee JY, Park HG, Kim YJ, Oh YK, Jung HC, Kim SI. 5,7-dihydroxy-3,4,6-trimethoxyflavone inhibits the inflammatory effects induced by Bacteroides fragilis enterotoxin via dissociating the complex of heat shock protein 90 and $\mathrm{IkB} \alpha$ and IkB kinase- $\gamma$ in intestinal epithelial cell culture. Clin Exp Immunol 2009; 155: 541-551

28 Gábor M. Anti-inflammatory and anti-allergic properties of flavonoids. Prog Clin Biol Res 1986; 213: 471-480

29 Seelinger G, Merfort I, Schempp CM. Antioxidant, anti-inflammatory and anti-allergic activities of luteolin. Planta Med 2008; 74: 1667-1677

30 Seelinger G, Merfort I, Wölfle U, Schempp CM. Anti-carcinogenic effects of the flavonoid luteolin. Molecules 2008; 13: 2628-2651

31 Serra A, Macià A, Romero MP, Reguant J, Ortega N, Motilva MJ. Metabolic pathways of the colonic metabolism of flavonoids (flavonols, flavones and flavanones) and phenolic acids. Food Chem 2012; 130: 383-393

32 Chen C. YC, Chen GW, Chen WYC. Molecular simulation of HER2/neu degradation by inhibiting Hsp90. J Chin Chem Soc 2008; 55: 297-302

33 Fu J, Chen D, Zhao B, Zhao Z, Zhou J, Xu Y, Xin Y, Liu C, Luo L, Yin Z. Luteolin induces carcinoma cell apoptosis through binding Hsp90 to suppress constitutive activation of STAT3. PLoS One 2012; 7: e49194

34 Hong Z, Cao X, Li N, Zhang Y, Lan L, Zhou Y, Pan X, Shen L, Yin Z, Luo L. Luteolin is effective in the non-small cell lung cancer model with L858R/T790 M EGF receptor mutation and erlotinib resistance. Br J Pharmacol 2014; 171: 2842-2853

35 Chen D, Bi A, Dong X, Jiang Y, Rui B, Liu J, Yin Z, Luo L. Luteolin exhibits anti-inflammatory effects by blocking the activity of heat shock protein 90 in macrophages. Biochem Biophys Res Commun 2014; 443: 326-332

36 Alfonso D, Kapetanidis I. Flavonoids from Iochroma gesnerioides. Pharm Acta Helv 1994; 68: 211-214

37 Tamura M, Hirayama K, Itoh K. Role of intestinal flora on the metabolism, absorption, and biological activity of dietary flavonoids. Bioscience Microflora 2003; 22: 125-131

38 Middleton jr. E, Kandaswami C. Effects of flavonoids on immune and inflammatory cell functions. Biochem Pharmacol 1992; 43: 1167-1179

39 Wang HK. The therapeutic potential of flavonoids. Expert Opin Investig Drugs 2000; 9: 2103-2119

40 Dechsupa S, Kothan S, Vergote J, Leger G, Martineau A, Beranger S, Kosanlavit R, Moretti JL, Mankhetkorn S. Quercetin, Siamois 1 and Siamois 2 induce apoptosis in human breast cancer MDA-MB-435 cells xenograft in vivo. Cancer Biol Ther 2007; 6: 56-61

41 Davies SP, Reddy H, Caivano M, Cohen P. Specificity and mechanism of action of some commonly used protein kinase inhibitors. Biochem J 2000; 351: 95-105

42 Harwood M, Danielewska-Nikiel B, Borzelleca JF, Flamm GW, Williams $G M$, Lines TC. A critical review of the data related to the safety of quercetin and lack of evidence of in vivo toxicity, including lack of genotoxic/ carcinogenic properties. Food Chem Toxicol 2007; 45: 2179-2205

43 Nagai N, Nakai A, Nagata K. Quercetin suppresses heat shock response by down regulation of HSF1. Biochem Biophys Res Commun 1995; 208: 1099-1105

44 Aalinkeel R, Bindukumar B, Reynolds JL, Sykes DE, Mahajan SD, Chadha $K C$, Schwartz SA. The dietary bioflavonoid, quercetin, selectively induces apoptosis of prostate cancer cells by down-regulating the expression of heat shock protein 90. Prostate 2008; 68: 1773-1789

45 Wang RE, Hunt CR, Chen J, Taylor JS. Biotinylated quercetin as an intrinsic photoaffinity proteomics probe for the identification of quercetin target proteins. Bioorg Med Chem 2011; 19: 4710-4720

46 Jeong JH, An JY, Kwon YT, Li LY, Lee YJ. Quercetin-induced ubiquitination and down regulation of Her-2/neu. J Cell Biochem 2008; 105: 585-595

47 East AJ, Ollis WD, Wheeler RE. Natural occurrence of 3-aryl-4-hydroxycoumarins. Part I. Phytochemical examination of Derris robusta (roxb) benth. J Chem Soc C 1969; 3: 365-373

48 Hadden MK, Galam L, Gestwicki JE, Matts RL, Blagg BSJ. Derrubone, an inhibitor of the Hsp90 protein folding machinery. J Nat Prod 2007; 70: 2014-2018

49 Li Y, Zhang T, Schwartz SJ, Sun D. New developments in Hsp90 inhibitors as anticancer therapeutics: mechanisms, clinical perspective and more potential. Drug Resist Updat 2009; 12: 17-27

50 El Hamidieh A, Grammatikakis N, Patsavoudi E. Cell surface Cdc37 participates in extracellular Hsp90 mediated cancer cell invasion. PLoS One 2012, 7: 1-9

51 Özgür A, Tutar Y. Heat shock protein 90 inhibitors in oncology. Curr Proteomics 2014; 11: 2-16

52 Hastings JM, Hadden MK, Blagg BS. Synthesis and evaluation of derrubone and select analogues. J Org Chem 2008; 73: 369-373
53 Mays JR, Hill SA, Moyers JT, Blagg BS. The synthesis and evaluation of flavone and isoflavone chimeras of novobiocin and derrubone. Bioorg Med Chem 2010; 18: 249-266

54 Khalid S, Paul S. Identifying a C-terminal ATP binding sites-based novel Hsp90-inhibitor in silico: a plausible therapeutic approach in Alzheimer's disease. Med Hypotheses 2014; 83: 39-46

55 Roux DG, Paulus E. Condensed tannins. 10. Isolation of (-)-butin and butein from wattle heartwoods. Biochem J 1961; 80: 62-63

56 Wang Z, Lee Y, Eun JS, Bae EJ. Inhibition of adipocyte inflammation and macrophage chemotaxis by butein. Eur J Pharmacol 2014; 738: 40-48

57 Lee SH, Seo GS, Sohn DH. Inhibition of lipopolysaccharide-induced expression of inducible nitricoxide synthase by butein in RAW264.7 cells. Biochem Biophys Res Commun 2004; 323: 125-132

58 Lee SH, Nan JX, Zhao YZ, Woo SW, Park EJ, Kang TH, Seo GS, Kim YC, Sohn $\mathrm{DH}$. Thechalcone butein from Rhus verniciflua shows anti-fibrogenic activity. Planta Med 2003; 69: 990-994

59 Pandey MK, Sandur SK, Sung B, Sethi G, Kunnumakkara AB, Aggarwal BB. Butein, a tetrahydroxychalcone, inhibits nuclear factor (NF)-kappaB and NF-kappaB-regulated gene expression through direct inhibition of IkappaBalpha kinase beta on cysteine 179 residue. J Biol Chem 2007; 282: 17340-17350

60 Chua AW, Hay HS, Rajendran P, Shanmugam MK, Li F, Bist P, Koay ES, Lim LH, Kumar AP, Sethi G. Butein downregulates chemokine receptor CXCR4 expression and function through suppression of NF- $k B$ activation in breast and pancreatic tumor cells. Biochem Pharmacol 2010; 80: $1553-1562$

61 Lau GT, Huang H, Lin SM, Leung LK. Butein downregulates phorbol $12-$ myristate 13-acetate-induced COX-2 transcriptional activity in cancerous and non-cancerous breast cells. Eur J Pharmacol 2010; 648: 24-30

62 Rajendran P, Ong TH, Chen L, Li F, Shanmugam MK, Vali S, Abbasi T, Kapoor S, Sharma A, Kumar AP, Hui KM, Sethi G. Suppression of signal transducer and activator of transcription 3 activation by butein inhibits growth of human hepatocellular carcinoma in vivo. Clin Cancer Res 2011; 17: 1425-1439

$63 \mathrm{Seo} \mathrm{YH}$. Butein disrupts Hsp90's molecular chaperoning function and exhibits anti-proliferative effects against drug-resistant cancer cells Bull Korean Chem Soc 2013; 34: 3345-3349

64 Seo YH, Jeong JH. Synthesis of butein analogues and their anti-proliferative activity against gefitinib-resistant non-small cell lung cancer (NSCLC) through Hsp90 inhibition. Bull Korean Chem Soc 2014; 35: 1294-1298

65 Kuo YF, Su YZ, Tseng YH, Wang SY, Wang HM, Chueh PJ. Flavokawain B, a novel chalcone from Alpinia pricei Hayata with potent apoptotic activity: involvement of ROS and GADD153 upstream of mitochondria-dependent apoptosis in HCT116 cells. Free Radic Biol Med 2010; 49: 214 226

66 Henderson BE, Kolonel LN, Dworsky R, Kerford D, Mori E, Singh K, Thevenot $H$. Cancer incidence in the islands of the Pacific. Natl Cancer Inst Monogr 1985; 69: 73-81

67 Steiner GG. The correlation between cancer incidence and kava consumption. Hawaii Med J 2000; 59: 420-422

68 Warmka JK, Solberg EL, Zeliadt NA, Srinivasan B, Charlson AT, Xing C, Wattenberg $E V$. Inhibition of mitogen activated protein kinases increases the sensitivity of A549 lung cancer cells to the cytotoxicity induced by a kava chalcone analog. Biochem Biophys Res Commun 2012; 424: 488-492

69 Sakai T, Eskander RN, Guo Y, Kim KJ, Mefford J, Hopkins J, Bhatia NN, Zi X, Hoang BH. Flavokawain B, a kava chalcone, induces apoptosis in synovial sarcoma cell lines. J Orthop Res 2012; 30: 1045-1050

70 Lin E, Lin WH, Wang SY, Chen CS, Liao JW, Chang HW, Chen SC, Lin KY, Wang L, Yang HL, Hseu YC. Flavokawain B inhibits growth of human squamous carcinoma cells: involvement of apoptosis and cell cycle dysregulation in vitro and in vivo. J Nutr Biochem 2012; 23: 368-378

71 Li X, Liu Z, Xu X, Blair CA, Sun Z, Xie J, Lilly MB, Zi X. Kava components down-regulate expression of $A R$ and $A R$ splice variants and reduce growth in patient-derived prostate cancer xenografts in mice. PLoS One 2012; 7: e31213

72 Ji T, Lin C, Krill LS, Eskander R, Guo Y, Zi X, Hoang BH. Flavokawain B, a kava chalcone, inhibits growth of human osteosarcoma cells through G2/M cell cycle arrest and apoptosis. Mol Cancer 2013; 12: 55

$73 \mathrm{Seo} Y H, \mathrm{Oh}$ YJ. Synthesis of flavokawain B and its anti-proliferative activity against gefitinib-resistant non-small cell lung cancer (NSCLC). Bull Korean Chem Soc 2013; 34: 3782-3786

74 Shibata S. A drug over the millennia: pharmacognosy, chemistry, and pharmacology of licorice. Yakugaku Zasshi 2000; 120: 849-862 
75 Hatano T, Kagawa H, Yasuhara T, Okuda T. Two new flavonoids and other constituents in licorice root: their relative astringency and radical scavenging effects. Chem Pharm Bull (Tokyo) 1988; 36: 2090-2097

76 Fu Y, Hsieh TC, Guo J, Kunicki J, Lee MY, Darzynkiewicz Z, Wu JM. Licochalcone-A, a novel flavonoid isolated from licorice root (Glycyrrhiza glabra), causes $\mathrm{G} 2$ and late-G1 arrests in androgen-independent PC-3 prostate cancer cells. Biochem Biophys Res Commun 2004; 322: 263-270

77 Xiao XY, Hao M, Yang XY, Ba Q Li M, Ni SJ, Wang LS, Du X. Licochalcone A inhibits growth of gastric cancer cells by arresting cell cycle progression and inducing apoptosis. Cancer Lett 2011; 1: 69-75

78 Chu X, Ci X, Wei M, Yang X, Cao Q Guan M, Li H, Deng Y, Feng H, Deng X. Licochalcone A inhibits lipopolysaccharide-induced inflammatory response in vitro and in vivo. J Agric Food Chem 2012; 60: 3947-3954

79 Landis-Piwowar KR, Huo C, Chen D, Milacic V, Shi G, Chan TH, Dou QP. A novel prodrug of the green tea polyphenol (-)-epigallocatechin-3-gallate as a potential anticancer agent. Cancer Res 2007; 67: 4303-4310

80 Palermo CM, Westlake CA, Gasiewicz TA. Epigallocatechin gallate inhibits aryl hydrocarbon receptor gene transcription through an indirect mechanism involving binding to a $90 \mathrm{KDa}$ heat shock protein. Biochemistry $2005 ;$ 44: 5041-5052

81 Yin Z, Henry EC, Gasiewicz TA. (-)-Epigallocatechin-3-gallate is a novel Hsp90 inhibitor. Biochemistry 2009; 48: 336-345

82 Li Y, Zhang T, Jiang Y, Lee HF, Schwartz SJ, Sun D. (-)-Epigallocatechin-3gallate inhibits Hsp90 function by impairing Hsp90 association with cochaperones in pancreatic cancer cell line Mia Paca-2. Mol Pharm 2009; 6: 1152-1159

83 Tran PL, Kim SA, Choi HS, Yoon JH, Ahn SG. Epigallocatechin-3-gallate suppresses the expression of Hsp70 and Hsp90 and exhibits antitumor activity in vitro and in vivo. BMC Cancer 2010; 10: 276

84 Khan N, Afaq F, Saleem M, Ahmad N, Mukhtar H. Targeting multiple signalling pathways by green tea polyphenol (-)-epigallocatechin-3-gallate. Cancer Res 2006; 66: 2500-2505

85 Li M, He Z, Ermakova S, Zheng D, Tang F, Cho YY, Zhu F, Ma WY, Sham Y, Rogozin EA, Bode AM, Cao Y, Dong Z. Direct inhibition of insulin-like growth factor-I receptor kinase activity by (-)-epigallocatechin-3-gallate regulates cell transformation. Cancer Epidemiol Biomarkers Prev 2007: 16: 598-605

86 Ramirez-Sanchez I, Aguilar U, Ceballos G, Villarreal F. (-)-Epicatechin-induced calcium independent eNOS activation: roles of Hsp90 and AKT. Mol Cell Biochem 2012; 370: 141-150

87 Halder B, Das Gupta S, Gomes A. Black tea polyphenols induce human leukemic cell cycle arrest by inhibiting Akt signalling. Possible involvement of Hsp90, Wnt/ $\beta$-catenin signalling and FOXO1. FEBS J 2012; 279 : 2876-2891

88 Malafronte N, Vassallo A, Dal Piaz F, Bader A, Braca A, De Tommasi N. Biflavonoids from Daphne linearifolia Hart. Phytochemistry Lett 2012; 5: 621-625

89 Marcu MG, Chadli A, Bouhouche I, Catelli M, Neckers LM. The heat shock protein 90 antagonist novobiocin interacts with a previously unrecognized ATP-binding domain in the carboxyl terminus of the chaperone. J Biol Chem 2000; 275: 37181-37186

90 Kimura S, Ito C, Jyoko N, Segawa H, Kuroda J, Okada M, Adachi S, Nakahata T, Yuasa T, Filho VC, Furukawa H, Maekawa T. Inhibition of leukemic cell growth by a novel anticancer drug (GUT-70) from Calophyllum brasiliense that acts by induction of apoptosis. Int J Cancer 2005; 113 : 158-165

91 Jin L, Tabe Y, Kimura S, Zhou Y, Kuroda J, Asou H, Inaba T, Konopleva M, Andreeff $M$, Miida T. Antiproliferative and proapoptotic activity of GUT-70 mediated through potent inhibition of Hsp90 in mantle cell lymphoma. British J Cancer 2011; 104: 91-100

$92 \mathrm{Lu} \mathrm{Y}$. Anthraquinones. In Xu R, Ye Y, Zhao W, editors. Introduction to natural products chemistry. London: CRC Press; 2012: 189-203

93 Huang PH, Huang CY, Chen MC, Lee YT, Yue CH, Wang HY, Lin H. Emodin and aloe-emodin suppress breast cancer cell proliferation through ER inhibition. Evid Based Complement Alternat Med 2013; 2013: 376123

94 Yan YY, Zheng LS, Zhang X, Chen LK, Singh S, Wang F, Zhang JY, Liang YJ, Dai CL, Gu LQ Zheng MS, Talele TT, Chen ZS, Fu LW. Blockade of Her2/neu binding to Hsp90 by emodin azide methyl anthraquinone derivative induces proteasomal degradation of Her2/neu. Mol Pharmaceut 2011; 8: 1687-1697

95 Fernand VE, Losso JN, Truax RE, Villar EE, Bwambok DK, Fakayode SO, Lowry M, Warner IM. Rhein inhibits angiogenesis and the viability of hormone-dependent and -independent cancer cells under normoxic or hypoxic conditions in vitro. Chem Biol Interact 2011; 192: 220-232
96 Vassallo A, Vaccaro MC, De Tommasi N, Dal Piaz F, Leone A. Identification of the plant compound geraniin as a novel Hsp90 inhibitor. PLoS One 2013; 8: e74266

97 Li J, Wang S, Yin J, Pan L. Geraniin induces apoptotic cell death in human lung adenocarcinoma A549 cells in vitro and in vivo. Can J Physiol Pharm 2013; 91: 1016-1024

98 Zhang $X-C$, Chen $P$, He B, Wang $N$, Shen Z-Q. Influence of geraniin on carbonic anhydrase type II (CA II) protein in osteoclasts. Shizhen Guoyi Guoyao 2013; 24: 804-807

99 Zhang X-C, Guo Y, He B, Wang N, Chen P, Shen Z-Q. Effect of geraniin on expression of carbonic anhydrase II mRNA in cultured osteoclasts. Zhongyao Yaoli Yu Linchuang 2013; 29: 32-34

100 Bing SJ, Ha D, Kim MJ, Park E, Ahn G, Kim DS, Ko RK, ParkJW, Lee NH, Jee $Y$. Geraniin down regulates gamma radiation-induced apoptosis by suppressing DNA damage. Food Chem Toxicol 2013; 57: 147-153

101 Yang Y, Zhang L, Fan X, Qin C, Liu J. Antiviral effect of geraniin on human enterovirus 71 in vitro and in vivo. Bioorg Med Chem Lett 2012; 22: 2209-2211

102 Serrano J, Puupponen-Pimia R, Dauer A, Aura AM, Saura-Calixto F. Tannins: current knowledge of food sources, intake, bioavailability and biological effects. Mol Nutr Food Res 2009; 53: S310-S329

103 Bhattacharjee B, Vijayasarathy S, Karunakar P, Chatterjee J. Comparative reverse screening approach to identify potential anti-neoplastic targets of saffron functional components and binding mode. Asian Pac J Cancer Prev 2012; 13: 5605-5611

104 Dal Piaz F, Vassallo A, Temraz A, Cotugno R, Belisario MA, Bifulco G, Chini MG, Pisano C, De Tommasi N, Braca A. A chemical-biological study reveals $C_{9}$-type iridoids as novel heat shock protein 90 (Hsp90) inhibitors. J Med Chem 2013; 56: 1583-1595

105 Beauchamp JK, Keast RS, Morel D, Lin J, Pika J, Han Q Lee CH, Smith AB, Breslin PA. Phytochemistry: ibuprofen-like activity in extra-virgin olive oil. Nature 2005; 437: 45-46

106 Margarucci L, Monti MC, Cassiano C, Mozzicafreddo M, Angeletti M, Riccio $R$, Tosco A, Casapullo A. Chemical proteomics-driven discovery of oleocanthal as an Hsp90 inhibitor. Chem Commun 2013; 49: 58445846

107 Zhao YS, Zhu TZ, Chen YW, Yao YQ Wu CM, Wei ZQ, Wang W, Xu YH. $\beta$ elemene inhibits Hsp90/Raf-1 molecular complex inducing apoptosis of glioblastoma cells. J Neurooncol 2012; 107: 307-314

108 Ohnishi K, Ohkura S, Nakahata E, Ishisaka A, Kawai Y, Terao J, Mori T, Ishii T, Nakayama T, Kioka N, Matsumoto S, Ikeda Y, Akiyama M, Irie K, Murakami A. Non-specific protein modifications by a phytochemical induce heat shock response for self-defense. PLoS One 2013; 83: e58641

109 Chao WW, Lin BF. Isolation and identification of bioactive compounds in Andrographis paniculata (Chuanxinlian). Chin Med 2010; 5: 17

110 Bao Z, Guan S, Cheng C, Wu S, Wong SH, Kemeny DM, Leung BP, Wong WS. A novel antiinflammatory role for andrographolide in asthma via inhibition of the nuclear factor- $k$ B pathway. Am J Respir Crit Care Med 2009; 179: 657-665

111 Lim JC, Chan TK, Ng DS, Sagineedu SR, Stanslas J, Wong WS. Andrographolide and its analogues: versatile bioactive molecules for combating inflammation and cancer. Clin Exp Pharmacol Physiol 2012; 39: 300-310

112 Abu-Ghefreh AA, Canatan H, Ezeamuzie CI. In vitro and in vivo anti-inflammatory effects of andrographolide. Int Immunopharmacol 2009; 9: 313-318

113 Liang FP, Lin CH, Kuo CD, Chao HP, Fu SL. Suppression of v-Src transformation by andrographolide via degradation of the $\mathrm{v}$-Src protein and attenuation of the Erk signaling pathway. J Biol Chem 2008; 283: 5023-5033

114 Liu SH, Lin CH, Liang FP, Chen PF, Kuo CD, Alam MM, Maiti B, Hung SK, Chi CW, Sun CM, Fu SL. Andrographolide downregulates the v-Src and $\mathrm{Bcr}-\mathrm{Abl}$ oncoproteins and induces Hsp90 cleavage in the ROS-dependent suppression of cancer malignancy. Biochem Pharmacol 2014; 87: 229-242

115 Druckova A, Mernaugh RL, Ham AJ, Marnett LJ. Identification of the protein targets of the reactive metabolite of Teucrin $A$ in vivo in the rat. Chem Res Toxicol 2007; 20: 1393-1408

116 Mohebati A, Guttenplan JB, Kochhar A, Zhao ZL, Kosinska W, Subbaramaiah K, Dannenberg AJ. Carnosol, a constituent of Zyflamend, inhibits aryl hydrocarbon receptor-mediated activation of CYP1A1 and CYP1B1 transcription and mutagenesis. Cancer Prev Res 2012; 5: 593-602

117 Hughes D, Guttenplan JB, Marcus CB, Subbaramaiah K, Dannenberg AJ Heat shock protein 90 inhibitors suppress aryl hydrocarbon receptor- 
mediated activation of CYP1A1 and CYP1B1 transcription and DNA adduct formation. Cancer Prev Res 2008; 1: 485-493

118 Zhou ZW, Xie XL, Zhou SF, Li CG. Mechanism of reversal of high glucoseinduced endothelial nitric oxide synthase uncoupling by tanshinone IIA in human endothelial cell line EA.hy926. Eur J Pharmacol 2012; 697: 97-105

119 Lamb J, Crawford ED, Peck D, Modell JW, Blat IC, Wrobel MJ, Lerner J, Brunet J-P, Subramanian A, Ross KN, Reich M, Hieronymus H, Wei G, Armstrong SA, Haggarty SJ, Clemons PA, Wei R, Carr SA. The Connectivity Map: using gene-expression signatures to connect small molecules, genes, and disease. Science 2006; 313: 1929-1935

120 Hieronymus $H$, Lamb J, Ross KN, Peng XP, Clement C, Rodina A, Nieto M, Du J, Stegmaier K, Raj SM, Maloney KN, Clardy J, Hahn WC, Chiosis G, Golub TR. Gene expression signature-based chemical genomic prediction identifies a novel class of Hsp90 pathway modulators. Cancer Cell 2006; 10: 321-330

121 Brandt GEL, Schmidt MD, Prisinzano TE, Blagg BSJ. Gedunin, a novel Hsp90 inhibitor: semisynthesis of derivatives and preliminary structure-activity relationships. J Med Chem 2008; 51: 6495-6502

122 Dal Piaz F, Malafronte N, Romano A, Gallotta D, Belisario MA, Bifulco G, Gualtieri MJ, Sanogo R, De Tommasi N, Pisano C. Structural characterization of tetranortriterpenes from Pseudrocedrela kotschyi and Trichilia emetica and study of their activity towards the chaperone Hsp90. Phytochemistry 2012; 75: 78-89

123 Gualtieri MJ, Malafronte N, Vassallo A, Braca A, Cotugno R, Vasaturo M, De Tommasi N, Dal Piaz F. Bioactive limonoids from the leaves of Azaridachta indica (Neem). J Nat Prod 2014; 77: 596-602

124 Morota T, Yang CX, Sasaki H, Qin WZ, Sugama K, Miao KL, Yoshino T, Xu LH, Maruno M, Yang BH. Triterpenes from Tripterygium wilfordii. Phytochemistry 1995; 39: 1153-1157

125 Salminen A, Lethonen M, Paimela T, Kaarniranta K. Celastrol: Molecular targets of Thunder God Vine. Biochem Biophys Res Commun 2010; 394: 439-442

126 Davenport A, Frezza M, Shen M, Ge, Y, Huo C, Chan TH, Dou QP. Celastrol and an EGCG pro-drug exhibit potent chemosensitizing activity in human leukemia cells. Int J Mol Med 2010; 25: 465-470

127 Deng YN, Shi J, Liu J, Qu QM. Celastrol protects human neuroblastoma SH-SY5Y cells from rotenone-induced injury through induction of autophagy. Neurochem Int 2013; 63: 1-9

128 Petronelli A, Pannitteri G, Testa U. Triterpenoids as new anticancer drugs. Anticancer Drugs 2009; 20: 880-892

129 Yang $H$, Chen D, Cui QC, Yuan X, Dou QP. Celastrol, a triterpene extracted from the Chinese "Thunder of God Vine", is a potent proteasome inhibitor and suppresses human prostate cancer growth in nude mice. Cancer Res 2006; 66: 4758-4765

130 Cheng G, Zhang X, Zhao M, Yan W, Chen X, Wang D, Xu Y, Du Z, Yu X. Celastrol targets mitochondrial respiratory chain complex I to induce reactive oxygen species-dependent cytotoxicity in tumor cells. BMC Cancer 2011; 11: 170

131 Peng B, Xu L, Cao F, Wei T, Yan C, Uzan G, Zhang D. HSP90 inhibitor, celastrol, arrests human monocytic leukemia cell U937 at G0/G1 in thiol-containing agents reversible way. Mol Cancer 2010; 9: 79

132 Kim K, Lee H, Han S, Lee Y, Choe J, Kim Y, Hahn J, Ro J, Jeoung D, Kim Y. Celastrol binds to ERK and inhibits FceRI signaling to exert an anti-allergic effect. Eur J Pharmacol 2009; 612: 131-142

133 Sha M, Ye J, Zhang LX, Luan ZY, Chen YB, Huang JX. Celastrol induces apoptosis of gastric cancer cells by miR-21 inhibiting PI3K/Akt-NFkB signaling pathway. Pharmacology 2014; 93: 39-46

134 Kannaiyan R, Manu KA, Chen, L, Li F, Rajendran P, Subramaniam A, Lam $P$, Kumar AP, Sethi G. Celastrol inhibits tumor cell proliferation and promotes apoptosis through the activation of c-Jun $N$-terminal kinase and suppression of PI3 K/Akt signaling pathways. Apoptosis 2011; 16: 1028-1041

135 Fan XX, Li N, Wu JL, Zhou YL, He JX, Liu L, Leung ELH. Celastrol induces apoptosis in gefitinib-resistant non-small cell lung cancer cells via caspases-dependent pathways and Hsp90 client protein degradation. Molecules 2014; 19: 3508-3522

136 Feng L, Zhang D, Fan C, Ma C, Yang W, Meng Y, Wu W, Guan S, Jiang B, Yang $M$. ER stress-mediated apoptosis induced by celastrol in cancer cells and important role of glycogen synthase kinase- $3 \beta$ in the signal network. Cell Death Dis 2013; 4: e715

137 Lu Z, Jin Y, Qiu L, Lai Y, Pan J. Celastrol, a novel HSP90 inhibitor, depletes Bcr-Abl and induces apoptosis in imatinib-resistant chronic myelogenous leukemia cells harboring T315I mutation. Cancer Lett 2010; 290: 182-191

138 Zhang T, Hamza A, Cao X, Wang B, Yu S, Zhan CG, Sun D. A novel Hsp90 inhibitor to disrupt Hsp90/Cdc37 complex against pancreatic cancer cells. Mol Cancer Ther 2008; 7: 162-170

139 Sreeramulu S, Gande SL, Göbel M, Schwalbe H. Molecular mechanism of inhibition of the human protein complex Hsp90-Cdc37, a kinone chaperone-cochaperone, by triterpene celastrol. Angew Chem Int Ed 2009; 48: 5853-5855

140 Zhang T, Li Y, Yu Y, Zou P, Jiang Y, Sun D. Characterization of celastrol to inhibit Hsp90 and Cdc37 interaction. J Biol Chem 2009, 284: 3538135389

141 Chadli A, Felts, SJ, Wang Q Sullivan WP, Botuyan MV, Fauq A, RamirezAlvarado M, Mer G. Celastrol inhibits Hsp90 chaperoning of steroid receptors by inducing fibrillization of the co-chaperone p23. J Biol Chem 2010; 285: 4224-4231

142 Zhang D, Xu L, Cao F, Wei T, Yang C, Uzan G, Peng B. Celastrol regulates multiple nuclear transcription factors belonging to Hsp90's clients in a dose- and cell type-dependent way. Cell Stress Chaperon 2010; 15 : 939-946

143 Zanphorlin LM, Alves FR, Ramos CH. The effect of celastrol, a triterpene with antitumorigenic activity, on conformational and functional aspects of the human $90 \mathrm{KDa}$ heat shock protein $\mathrm{Hsp} 90 \alpha$, a chaperone implicated in the stabilization of the tumor phenotype. Biochim Biophys Acta 2014; 1840: 3145-3152

144 Pyo JS, Roh SH, Kim DK, Lee JG, Lee YY, Hong SS, Kwon SW, ParkJH. Anticancer effect of betulin on a human lung cancer cell line: a pharmacoproteomic approach using 2D SDS PAGE coupled with nano-HPLC tandem mass spectrometry. Planta Med 2009; 75: 127-131

145 Ding L, Xu FC, Wang H, Ou QM. Studies on chemical constituents from Patrinia heterophylla Bunge and their cytotoxicity in vitro. J Northwest Normal University (Natural Science) 2007; 43: 62-65

146 Wei DF, Wei YX, Cheng WD, Yan MF, Su G, Hu Y, Ma YQ Han C, Lu Y, Cao HM, Bao YC. Proteomic analysis of the effect of triterpenes from Patrinia heterophylla on leukemia K562 cells. J Ethnopharmacol 2012; 144 : 576-583

147 Haginaka J, Kitabatake T, Hirose I, Matsunaga H, Moaddel R. Interaction of cepharanthine with immobilized heat shock protein $90 a$ (Hsp90 $\alpha$ ) and screening of Hsp90 $\alpha$ inhibitors. Anal Biochem 2013; 434: 202-206

148 Rogosnitzky M, Danks R. Therapeutic potential of the biscoclaurine alkaloid, cepharanthine, for a range of clinical conditions. Pharmacol Rep 2011; 63: 337-347

149 Tang J, Feng Y, Tsao S, Wang N, Curtain R, Wang Y. Berberine and Coptidis rhizome as novel antineoplastic agents: a review of traditional use and biomedical investigations. J Ethnopharmacol 2009; 126: 5-17

150 Rahmatullah M, Jahan R, Bashar ABMA, Al-Nahain A, Majumder S, Islam T, Das PR. A review on berbamine - a potential anticancer drug. J Pharm Pharm Sci 2014; 3: 95-110

151 Diogo CV, Machado NG, Barbosa IA, Serafim TL, Burgeiro A, Oliveira PJ. Berberine as a promising safe anticancer agent - is there a role for mitochondria? Curr Drug Targets 2011; 12: 850-859

152 Jabbarzadeh KP, Rahmat A, Ismail P, Ling KH. Targets and mechanisms of berberine, a natural drug with potential to treat cancer with special focus on breast cancer. Eur J Pharmacol 2014; 740: 584-595

153 Sun JR, Zhang XH, He ZW, Gu Y, Yu YZ, Fang YM, Lu QH, Dong QH, Xu RZ. The mechanism of apoptosis of chronic myeloid leukemia cells induced by the novel p210 bcr/abl inhibitor berbamine. Zhonghua Yi Xue Za Zhi 2006; 86: 2246-2251

154 Dal Piaz F, Vassallo A, Chini MG, Cordero FM, Cardona F, Pisano C, Bifulco G, De Tommasi N, Brandi A. Natural iminosugar (+)-lentiginosine inhibits ATPase and chaperone activity of hsp90. PloS One 2012; 7: e43316

155 Pastuszak I, Molyneux RJ, James LF, Elbein AD. Lentiginosine, a dihydroxyindolizidine alkaloid that inhibits amyloglucosidase. Biochemistry 1990; 29: 1886-1891

156 Ren Y, Yuan C, Chai HB, Ding Y, Li XC, Ferreira D, Kinghorn AD. Absolute configuration of (-)-gambogic acid, an antitumor agent. J Nat Prod 2011; 74: 460-463

157 Zhang L, Yi Y, Chen J, Sun Y, Guo Q Zheng Z, Song S. Gambogic acid inhibits Hsp90 and deregulates TNF- $\alpha /$ NF- $k$ B in HeLa cells. Biochem Biophys Res Commun 2010; 403: 282-287

158 Davenport J, Manjarrez JR, Peterson L, Krumm B, Blagg BS, Matts RL. Gambogic acid, a natural product inhibitor of Hsp90. J Nat Prod 2011; 74: 1085-1092 